eye the evening before at conjunction, save that clouds intervened. And this one day added to the twenty days actually recorded would make the period of visibility on this occasion three full weeks.

At the brightest the planct was fully equal to a Ist magnitude star, and for more than a week as bright as a Arietis, two hours to the east of it, with which I frecluently compared it. It was brighter than Saturn (also in the twilight) for several evenings, and was seen casually, as any other star. would be seen, as I came up town from busincss, for more than a weck. As a friend of mine remarked, "it could be seen with half an eye."

As regards the earlier observations of the table, it will be noted that the planet was seen for thirteen days in the spring of 1877 , thongh first looked for only five days before it reached its rrcatest eastern elongation. It was again beautifully seen several mornings near the close of September, 1878 , coming twice into conjunction with Venus during that time, though the observa. tions were not continued so as to try how long it could be followed.

Finally, in January, 1879, though the position of the ecliptic was not favourable, an elongation of over $24^{\circ}$ and splendid skies cnabled me to follow Mercury for twenty two days in succession, or while he made a full one-fourth of a revolution round the sun?

If any interest attaches to this communication it will surely not be from a : uperfluous attempt to show that Mercury at special times becomes visible to the naked eye; but rather from its giving certain clefinitc facts as to the exact lentis of time the planet has been observed, at the several apparitions indicated. The astronomical conditions of these returns of the planet may be made out with the help of an ephemeris and a celestial globe. I need only add that the observations were made in a climate where hours favourable for astronomical work may frequently be numbered by the hundred monthly, and own that the conditions of sky and atmosphere under which they were made were generally favourable to the best results.

T. D. SIMONTON

St. Paul, Minnesota, U.S. A., May I

\section{Specialised and United Palæontological Research}

Is your report of Prof. IIuxley's lecture on "The Coming of $\lambda$ ge of the Origin of Species" there was one sentence which was pregnant with import to every tiue devotee of natural history and to every believer in the doctrine of evolution, to wit, that "primary and direct evidence in favour of cvolution can be furnished only by palæontology."

Knowing that this is so, I ask, Do there exist amongst all our scientific associations delegated committces whose function it is to watch and fuster palzontological research by every possible weans? Seeing that so much depends on this kind of cvidence, it is surprising that we hear so little of the recults of any united efforts in ti.is clirection. What we generally hear of are the out come mostly of private and individual inquiry. And since so much has already been done in this field of investigation by mere individual effort that the " missing links" between widely separated groups of the higher mammalia (not includirg man) have been discovered so abundantly that it can be said with respect to these, in the words of Prof. IIuxley, "Lvolution is no longer a speculation, but a statement of historical fact "- - since this is the result of private and individual effort, what might not be achieved by united and organised research !

It is a truism that divivion of labour is the best means of specialising and perfecting any work, and an equally trite saying, that "union is strength ;" yet in this, one of the urost important of all the fields of biological stucly, we do not hear of a palcontological society or committec.

What could such a society or committec effect? it may be asked. Would it be cxpected to take hammer, picliaxe and spade in hand and wander over the wide world in exploration? Cortainly not. But remaining at home, it could direct the efforts of private explorers, delegate officers of its own, equipped with the means of (uestioning the geological record in different part of the globe, unite with lindred associations in solving problems too arduous for the single resources of one society, diriding alike the expenses and the spoil. Surcly it would gratify the heart of every naturalist to learn if palixontological rescarch had asumed this scrious and enerretic form.

Ilow many opportunitics are allowed to slip that might be turned to cxcellent account! Wars are carried on in countries as yet geologically unexplcred, and for want of such a society as I have named there has been no one employed to accompany our armies in the causc of this branch of science. Railways and other engineering works have been carried out in such regions, but no one has been employed to watch the operations in the name of palxontology. Travellers go and return withcut having been furnished with data to "gujde researches that might have been intclligently prosecuted in the cause of science.

Will not our leaders in natural science arouse themselves to organised and specialised research in this all-important field of palæontology?

Stafford, May 29

\section{The Meteorology of South Australia}

[WE have been asked to publish the following correspondence on an article on this subject in NATURE, vol, xxi. p. 28I.]

$$
\text { South Australia, the Trasury, Adelaide, }
$$$$
\text { April I } 5,1880
$$

SIR, - I have to thank you for the extract from NATURE, inclosed in your despatch No, 7,842 , dated January 31 last, which was duly referred to the IIonorable the Minister of Edtication, and has been perused by the Postmaster-General, \&c., and observer, Mr. Todi, C.M.G., a copy of whose observations and remarks upon this subject I now forward for your information and that of the Editor of NATURE. I am, sir, your obedient servant,

Sir Arthur Blyth, K.C.M.G., Agent-General for South Australia, London

\section{Post and Telegraph Department}

Meno. on Letter from Agent-General

Meteorological OBSERVATroNs

The writer of the article in NATURE had evidently not received the volume for 1878 , but only the monthly numbers. In the volume, as the Agent-General, to whom I have sent a copy, will see, I have given the results of the observations at Port Darwin, Alice Springs, Eucla, Cape Borda, Mount Gambier, and Cape Northumberland. As the Minister is aware, I have recoinmended that instruments should be supplied to several additional places, which will really give effect to what the writer in NATURE very properly urges. The extent and form in which the observations made at our institutions should be published require consideration on the score of economy of printing ; and, as the Minister is aware, the observatory is altogether undermanned for the work now done, and if it were not for my own personal exertions in doing that which might be intrusted to assistants, we could not do what is done. With regard to the other suggestion, I had freviously decided on correlating the rainfall and wheat-yield in different districts, in addition to the table, which takes the colony as a whole, now given.

The form in which our observations are publishied and dis. cussed appears to give general satisfaction, and this will be greatly increased when we have the continuous self-recording instruments I have recommended should be obtained.
April 4
(Signed)
C. ToDn
P. M. G. and Supt. T.

[Mr. Todd is correct in supposing that the volume for 1878 was not before us-not having been then received-in writing the article on the "Meteorology of South Australia" in NiTURE, vol. xxi. p. $28 \mathrm{r}$, but only the monthly numbers. The volume has, however, been received quite recently, which, in view of the highly important additions it contains, referred to by Mr. Todd, we shall take an early opportunity of noticing. It give: us the highest satisfaction to learn that of the two points we drew attention to half a year ago, the one relating to the establishment of additional stations had not only been resolved on, but actually carried out in the beginning of 1878 , and as regards the other one, referring to the correlating of the rainfall and-athe wheat-yicld in different districts, in addition to the table which deals with the colony as a whole, it had previously been decided by Mr. Todd to discuss the data in the manner suggested. - ED.]

\section{Comparative Curves in Terrestrial Magnetism}

Ai the comparison of curves obtained at distant stations is at present one of the most important desiderata for the study of terrestrial magnetism, I forward to you traces of two photographs obtained on March 17 last at Vicnna and at Stonyhurst. The storm is a remarkable one, and the curves offer a striking illustration of the sinultancous action of the disturbing force on 
two magnets many miles apart. The action of the force appears to have been somewhat more vigorous at Stonyhurst than at Vienna, yet not only the great inflections, bat even the slight irregularities of the curves were synchronous.

The trace of the Viema magnctograph is taken from the May number of the Zeitschift dior östcreichischen Gesellschaft firr Meteorologie, kindly forwarded by Ur. Hann.

The range between the maximum and primary minimum at 5h. $45 \mathrm{~m}$. p.m. G.M.T. was $33^{\prime} \cdot 7$ at Vienna, and $42^{\prime} \cdot \mathrm{I}$ at Stonyhurst; and between the same maximum and the secondary minimum at 10h. $45 \mathrm{~m}$. p.m. was $24^{\prime} \cdot 1$ at Vienna, and $34^{\prime \prime} \mathrm{O}$ at Stonyhurst.

Both the sclf-recurling magnetographs were made by Adie, and the time scale is the same for both curves; it is therefore very easy to identify the synclironous movements.

At Stonyhurst G.M.T. is adopted, and the longitude of Viemna is $I$ h. $5 \mathrm{~m} .3 \mathrm{r} \cdot 3$. E. of Greenwich.

Stonyhurst Observatory, May 27

\section{Luminous Painting}

Nil novi sub sole.-The Japanese, nine hundred years ago, secm to have been practically acquainted with the art of luminous painting, and thus to have anticipated Mr. Balmain. In looking through the article "ye" (pictures) in the SinicoJapanese Fncyclopædia, "Wakan san sai dzu-ye" (illustrated Description of the Three Powers, i.e., Heaven, Earth, and Man), I recently came upon a passage, of which the following slightly condensed rendering may perhaps be of some interest to your readers :-

"In the Rui-yen (Lei-yuen, Garden of Sundries-a sort of Chinese Collectanea) we read of one Sü Ngoh, who had a picture of an ox. Fivery day the ox left the picture-frame to graze, and returned to sleep within it at night. This picture came into the possession of the Emperor T'ai Tsung, of the Sung dynasty (A.D. 976-998), who showed it to his courticrs, and asked them for an explanation, which none of them, however, could give. At last a certain Buddhist priest said that the Japanese fornd some nacreotis substance within the flesh of a kind of oyster they piclied up when the rocks were bared at low tide, and that they groum this into colour-material, and then painted pictures with it which were invisible by day and luminous by night."

"No doubt," adds the author of the Encyclopxdia, "when it is said that the ox left the picture-frame during the day to go a.grazing, it is meant simply that during the day the figure of the ox was not visible."

Arts Club, June I

\section{Brain Dynamics}

There are probably aunng the readers of NATURE some believers in the Freedom of Volition, to whom the discussion on the above subject has not hitherto appeared to reach the knottiest point of the controversy.

The more old-fashioned supporters of the doctrine of Frec Will frcquently insisted on the sense of Responsibility as the crucial proof that the will is free, probably because few of their opponents were ready to face the possible, or supposed, moral consequences of the denial of responsibility. The proof is essentially weak, and Mr. Romanes has well exhibited its weakness in Nature, vol. xxii. p. 76. His "Prince of Denmark" has intleed so little of method in his madness that $I$ am nat disposed to think it curious that both I'rof. Clifford and Mr. Tolver Freston should have left him out of their play. He may well exclaim : "What should such fellows as I do, crawling between earth and heaven? We are arrant hnaves all ; believe none of us." Surely the sense of Responsibility is not the origin, but is one of the results of the Scnsc of Freedom. 1.ogically the Sense of Freedom is the justification of the sense of responsibility. His torically it is, no doubt, its antecedent; for while both are, as much as any other faculties of brute and man, results of evolution, the refincment of the conception of morality, and therefore probably the conception itself, has evidently originated long after the conscionsness of volition. Experimentally the sense of responsibility is wealiened or destroyed, either psychol igically, as where the freedom of the actor is controlled, or physiologically, as where volition is suspended in sleep, or is impaired by lesion of the anterior lobes of the brain, in all which cases the sense of responsibility suffers corresponding loss. It seems to me strange that Mr. Romanes should suppose the doctrine of Free Will to bave been conceived and continued in order to justify that Moral Sense which is esentially a consequence of it (though capable finally of being presented as onc among other motives in certain acts of volition). It lies with those who think with Mr. Romanes to account, on their own hypothesis, for the development of so universal, obtrusivc, irrational, and indeed "nonsensical" an instinct as, according to that bypothesis, the sense of responsibility is. Others will see in it a rcsult of the Sense of Freedom of Volition, when combined with the intellectual perception of the consequences, to the individual or to the race, of human acts (the latter perception being the cumulative result of inherited experiences). This Sense of Freedom of Volition is the real II amlet.

We possess, or appear to ourselves to possess, the conscious ness of the power of choosing between alternative motives. It is unsafe merely to give the lie direct to this consciousness, lest we thereby destroy the validity of the cridence, also derived through consciousness, of all those facts on which any law of nature, and Causal Sequence itself, is based. The consciousness of power is derjved from the sense of work done, as against resistance, e.g., the conscionsness of muscular power is derived from a class of sensations produced on the organim by resistance, these sensations being created by, and consequently associated with, the conversion of potential energy stored up in the brain into kinetic energy transmitted through the nerres and muscles, an:t it bears no psychological resemblance to the consciousness of sensations of which the brain is the passive recipient. Similarly, the consciousness of the power of volition is derived from the sense of work done, in this case wholly within the brain, in the selection between alternative motives, and it bears no psychological resemblance to the consciousness of the motives them. selves. And so, too, just as the sense of lassitude is produced by excess of work done as against physical resistance, so is a sense of discomfort produced by expenditure of potential energy, when acts of volition are performed against powerful emotions.

It appears to me that the Necessitarian should be able on his part to show that this senese of work performed in choosing betwecn motizes is fictitions, or that the energy above mentioned has no cxistence. This will not lo done solely by holding even the terrors of omnipotent Causal Sequence over the head of the advocate of Free Will. The Jatter considers volitions to be, not indeed "uncaused" in the sense of occurring without antecedent cmotions, or without expencliture of energy in choosing between the enotions, yet not t, be rigidly determined by those emotions. IIe need not inquire whether a man be "unfortunate" in the capricious character of human acts as compared with other phenomena. But he on his part bas to show (and ccrtainly no scientific mind will underrate the magnitude of the task) that phenomena of volition do, paradoxical as it may seem, constitute a class by themselics, their relation to plisysical causation being pcrhaps comparable to that in which the phenomena of life stand to the laws of inorganic chemistry, a relation of addition, not of contradiction.

W. CremFit Ley

I shotind like to state, in 'reply to Mr. George Romanes' letter (NATUKF, vol. xxii. p. 75), that the question of "Responsibility" was left out of my letter (NATURE, vol. xxii, p. 29) partly because it seemed to me a separate or somewhat distinct subject, and partly from the fact that this matter had been already considered by me in connection with a paper on "Nata. ral Science and Morality," to be publiwhed in the Fournal of Sicince for July next; and to this, therefore, I would venture to refer those who may be interested in this question.

I may merely conclude by saying that, while otherwise fully endorsing Mr. Romanes' letter, there is only one point on which I should be disposed to disagree with him, viz., in regard to his suggested view that the doctrine of strict causal sequence in nature would tend to show the feelings of Responsibility, Praise, and Blame to be "de titutc of any rational justification." For there appear to me to be groundi for believing that a scientific and rational explanation of these feclings exists.

Loncion, June

S. 'Tolver Prestoxi

\section{Vortex Atoms}

While thanking Mr. G. II. Marwin for his observations on one or two passages in my paper "On the Physical Aspects of the Vortex-Atom Theory," which, as they stand, may no doubt tend to conrcy an incxact impression, I may state that the illus- 